\title{
Dem Andenken Adolf Vossius
}

Am 28. VI. wurde Adolf Vossius kurz nach Vollendung seines 70. Lebens-jahres von einem langen schweren Leiden durch den Tod erlöst. Nachdem er in den letzten Jahren schon verschiedentlich durch Krankheit gezwungen worden war, sich vorübergehend beurlauben zu lassen, trat er am 1. April 1924 in den definitiven Ruhestand.

Er war am 10. II. 1855 in Zempelburg i. Ostpreußen als Arztsohn geboren. Nachdem er das Gymnasium in Konitz besucht hatte, widmete er sich dem Stu-dium der Medizin in Königsberg, wo er auch das Staatsexamen ablegte. Von 1879 - 81 war er unter A. v. Hippel Assistent an der Gießener Augenklinik. Nachdem er kurze Zeit zum Zweck anatomischer Studien bei Merkel in Rostock und Schwalbe in Königsberg gewesenwar, und nachdem er ebeníalls kurze Zeit unter Leber in Göttingen gearbeitet hatte, wurde er Assistent Jacobsons an der Königsberger Universitäts-Augenklinik. Dort habilitierte er sich 1882 und wurde 1887 zum außerordentlichen Professor ernannt. Nachdem Jacobson gestorben war, leitete er im Wintersemester 1889/90 in Vertretung die Königsberger Klinik. Am 1. IV. 1890 folgte er einem Ruf an die Universität Gießen als Nachíolger A. von Hippels. Von da ab widmete er seine ganze Kraft der Gießener Klinik, die ihm im Laufe der Jahre so sehr ans Herz wachsen sollte. Bei seinem Amtsantritt übernahm er die Klinik in äußerst primitivem Zustand. Sie befand sich damals zusammen mit der Chirurgischen Klinik in der alten Kaserne. Die engen und unhygienischen $\lambda \Gamma$ erhältnisse dort ließen in ihm den Entschluß reifen, mit alien Mitteln den Bau einer neuen modernen Augenklinik zu erreichen. Mit großer Ausdauer und unter heítigen Kämpfen setzte er schließlich seinen Plan Ill die Tat um, so daß er 1907 die neue Klinik beziehen konnte. Die neue Klinik 1st sein ureigenstes Werk. Mit uiiendlicher Liebe und Sorgfalt hat er die Plane bis in alle Einzelheiten durchdacht und durchgearbeitet, so daß auch heute noch nach fast 20 Jahren die ganze Anlage als geradezu mustergültig bczcichnet werden kann. In seiner Klinik ging cr ganz auf. Adolf Vossius war Klinikcr vom alten Schlag. Seine großen Erfahrungen stellte er ganz in den Dienst seiner Patienten. Es war eine Freude, die Vossiussch.cn Bulbusoperationen, insbe-sondere seine Staroperationen zu sehen. Es war ein sehr exakter Beobachtcr seiner Kranken, und so hat er als erster die Kontusionsringtrübung der Linse

154 Dem Andenken Adolf Vossius.

beschrieben und die „Keratitis interstitialis centralis annularis”. In der oph-thalmologischen Literatur war er zu Hause wie kaum ein anderer, dabei kam ihm seingeradezu phänomenales Gedächtnis zu statten. Er wußte von Arbeiten, die schon vor zehn Jahren und länger erschienen waren, auf das genaueste, was sie enthielten und wo sie zu íinden waren. Er selbst ist in der

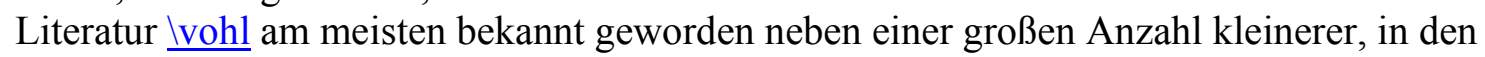
verschie-denen ophthalmologischen Zeitschriften erschienenen Arbeiten durch sein umíangreiches Lehrbuch, von dem vier Auflagen erschienen sind und dessen dritte Auflage auch ins Russische und Japanische übersetzt wurde. Ferner gab Vossius die Sammlungen zwangloser Abhandlungen aus dem Gebiete der Augenheilkunde heraus, von denen zehn Bände erschienen sind. 
Der Hörsaal Vossius' war immer von Hörern stark besetzt. Das hatte zwei verschiedene Gründe. Er stellte an den jungen Mediziner sowohl beim Prakti-zieren als auch im Examen außerordentlich hohe Anforderungen. Das war es aber nicht allein. Sein fließender und fesselnder Vortrag ließ die Studierenden sein Kolleg gerne besuchen, und seine Schüler, die mitBangen zu ihm ins Examen gegangen sind, haben es ihm später gedankt, daß er ihnen so vieles für die Praxis mitgegeben hat.

I. In Vossius ist ein Mann von seltener Pflichttreue dahingegangen dessen ganzes Sein seinem Beruf und seinen Patienten gait. Er war vom altpreußischen Geist erfüllt

deshalb konnte er sich auch mit der neuen Zeit durchaus nicht abfinden. Schon zu Beginn des Krieges wurde er schwer durch den Tod seine.1-ältesten Sohnes getroffen. Bis zum Ende glaubte er unerschütterlich an den Sieg der deutschen Sache und empfand deshalb den ihm gänzlich unerwartet hereinbrechenden Zusammenbruch um so schwerer. Dazu litt er zuletzt schwer auch unter seinen körperlichen Leiden so daß der Tod der dieses arbeitsreiche Leben beschloß schließlich als eine Erlösung kam. Sein Andenken in Ehren! Gros Gießen. 